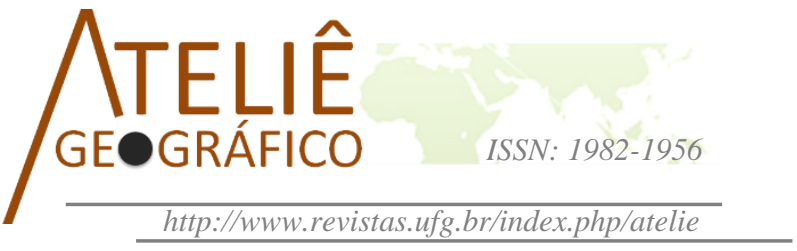

\section{Características do processo de licenciamento ambiental em Goiás: desafios do setor de mineração}

\author{
Characteristics of the environmental licensing process in the \\ State of Goiás: challenges of the mining sector
}

\section{Características del proceso de obtención de licencias ambientales en Goiás: desafíos del sector minero}

\author{
Dalmo de Araújo \\ Secretaria de Meio Ambiente, Recursos Hídricos, Infraestrutura, Cidades e \\ Assuntos Metropolitanos do Estado de Goiás \\ dalmodearaujo@gmail.com
}

\begin{abstract}
Resumo
O processo de licenciamento ambiental é de conhecimento restrito e grande parte da população desconhece a sua forma de operação básica. Este artigo tem por objetivo caracterizar o processo de licenciamento ambiental do setor de mineração em Goiás. Dentre as características mais relevantes identificadas, cita-se a ausência de critérios legais para a classificação das atividades minerárias para o licenciamento ambiental. A pesquisa consistiu em revisão da legislação ambiental aplicada ao setor de mineração e análise de informações sobre processos de licenciamento ambiental junto ao órgão ambiental de Goiás, período entre 2011-2014. A definição formal do processo de licenciamento ambiental e sua consequente divulgação em formato didático e acessível a todos, afloram como os maiores desafios.
\end{abstract}

Palavras-chave: Licenciamento ambiental. Legislação ambiental. Mineração em Goiás.

\begin{abstract}
The environmental licensing process is of restricted knowledge and most of the population is unaware of its basic operation. The aim of this article is to characterize the environmental licensing process of the mining sector in the Goias State. Among the most relevant characteristics identified is the absence of legal criteria for the classification of mining activities for the environmental licensing. The research consisted in a review of the environmental legislation applied to the mining sector and analysis of information on environmental licensing processes before the environmental authority of the Goias State between 2011-2014. The formal definition of the environmental licensing process and its consequent disclosure in didactic format and accessible to all, emerges as the main challenges.
\end{abstract}

Keywords: Environmental Licensing. Environmental legislation. Mining at Goias State. 


\begin{abstract}
Resumem
El proceso de obtención de una licencia ambiental no es ampliamente conocido, y gran parte de la población desconoce su operación básica. Este artículo tiene como objetivo caracterizar el proceso de licenciamiento ambiental en el ámbito del sector minero en Goiás. Entre las características más relevantes se identificó la ausencia de criterios legales para clasificar las actividades mineras en pos de la obtención de la licencia. Para llevar a cabo la investigación, se revisó la legislación ambiental aplicada al sector de la minería y se analizó la información sobre los procesos de obtención de licencias ambientales frente al organismo ambiental de Goiás en el período 2011-2014. Los mayores desafíos fueron la definición formal del proceso de licenciamiento ambiental y su consecuente divulgación en formato didáctico y accesible a todos.
\end{abstract}

Palabras clave: Licenciamiento ambiental. Minería en Goiás. Legislación ambiental.

\title{
Introdução
}

A recente ocorrência do maior acidente ambiental da atividade de mineração no Brasil, em 05 de novembro de 2015, após o rompimento de uma barragem de contenção de rejeitos de minério de ferro pertencente à empresa Samarco Mineração S.A., situada no município de Mariana, em Minas Gerais, trouxe para o centro de debate das questões ambientais, a pauta da "mineração e meio ambiente" em suas mais diversas faces. Dentre elas, o licenciamento ambiental da mineração e da forma que é realizado o licenciamento pelos órgãos ambientais no Brasil.

O licenciamento ambiental, como descreve Loureiro (2010, p.16), "é um processo institucionalizado e atributo exclusivo do Estado que busca garantir certos padrões de desenvolvimento humano, social e de proteção e preservação ambiental, cujos critérios para execução são definidos segundo motivações políticas e econômicas e parâmetros oriundos do conhecimento científico".

A problemática do licenciamento é extensa e diversificada, passando pelo estabelecimento de critérios de qualidade e eficiência do licenciamento realizado, distinção de categorias de projetos ambientais exigidos, monitoramento e fiscalização das atividades licenciadas, evolução da legislação ambiental específica e modo de operação geral do processo de licenciamento, relação entre tipos de licenças ambientais e fases de licenciamento aplicáveis, infraestrutura do órgão ambiental, realização de concursos públicos, formação de equipes multidisciplinares e capacitação continuada de técnicos e analistas ambientais, dentre outros aspectos vinculados ao melhoramento das condições de trabalho, gestão ambiental pública e educação no licenciamento.

Gestão ambiental pública, entendida aqui em seu sentido abrangente dado por Quintas (2004, p.118), “como processo de mediação de interesses e conflitos (potenciais ou explícitos) entre atores sociais que agem sobre o meio físico natural e construído, objetivando garantir o direito ao meio ambiente ecologicamente equilibrado". Quanto à educação no licenciamento diz respeito aqui à "educação para cidadania" e de acordo com a orientação 
dada por Jacobi (2003, p.197, grifo nosso), por exemplo, ao apontar para o "desafio do fortalecimento da cidadania para a população como um todo, e não para um grupo restrito, se concretiza a partir da possibilidade de cada pessoa ser portadora de direitos e deveres e se converter, portanto, em autor corresponsável na defesa da qualidade de vida".

O licenciamento ambiental é uma área de estudo que não possui uma autonomia disciplinar. Em sua prática, o licenciamento ambiental do setor de mineração é multifacetado. Possui características variadas e também peculiares a cada contexto ambiental tratado e vinculado à rigidez locacional da ocorrência mineral. E, por isso demanda contribuições provenientes das mais diversas áreas do conhecimento, principalmente da geologia, geografia, biologia, química, sociologia, engenharia, direito ambiental e educação. Assim, o licenciamento é um vasto campo de pesquisa interdisciplinar e, por assim dizer, que exige cada vez mais uma visão transdisciplinar para reflexão e encaminhamento das decisões ambientais acerca da viabilidade ambiental de instalação de determinado empreendimento minerário. Segundo Ponzilacqua (2015, p.32) entende-se por transdisciplinar "que o diálogo deve superar o conceito de disciplina, enquanto espaço de contribuição teórica e mesmo de aplicação muito definido, estanque e incomunicável'”. Pressupõe-se assim, que as decisões sobre o meio ambiente seriam tanto quanto melhores quando sustentadas pelo diálogo. Não somente do diálogo que deve constituir as relações do ser humano com os seus semelhantes, ou da necessária comunicação entre grupos e departamentos temáticos responsáveis pelo licenciamento dentro da organização e organograma de um órgão ambiental, por exemplo. Mas, do diálogo entre a sociedade e a natureza, cujo documento de maior representatividade aqui vislumbrado na área do licenciamento seria o projeto ambiental realizado. $\mathrm{O}$ projeto ambiental neste contexto seria uma espécie de elemento mediador entre a sociedade e a natureza. Projetos ambientais "ruins" contribuem para a degradação ambiental.

Mas, o que seria um projeto ambiental "ruim"? Note-se, a exemplo do que aponta Freire (2011, p.26) de que "a memorização da descrição do objeto não se constitui em conhecimento do objeto". De forma análoga, a memorização da descrição do impacto ambiental também não se constitui em conhecimento sobre o impacto ambiental. Um profissional que trabalha com meio ambiente, consultor ou analista ambiental que produz ou analisa um projeto ambiental de licenciamento do setor mineral sem prévia atividade de campo (ou vistoria técnica), ambos, por assim dizer correm um grande risco (ambiental): o distanciamento da realidade. Afastamento este representado pela reprodução indiscriminada do "já dito", escrito e interpretado por outrem, por meio do qual o "recurso metodológico do Ctrl-C e Ctrl-V" seria amplamente utilizado para a reprodução da natureza. De forma "ingênua" (para utilizar aqui um termo recorrente em Paulo Freire), os supostos autores de tal procedimento prescindem da negociação crítica com a realidade e com a natureza, para a "leitura do mundo" (FREIRE, 2011). Ou seja, contribuem para a degradação ambiental, mesmo que de forma não intencional ou "não consciente" pelo mau exemplo profissional disseminado. Para o licenciamento ambiental do setor mineral, a vistoria técnica em campo é necessária para verificação das informações ambientais declaradas em projeto. Em muitos casos, o distanciamento da realidade é tão grande que o indeferimento da solicitação de licença é imediato, haja vista a inviabilidade ambiental constatada em campo. Desta forma, a abordagem da mineração no licenciamento não pode prescindir da construção de uma relação 
“sociedade-natureza" e como aponta Jacobi (2005), que se manifeste em valores éticos, educacionais e de cidadania.

Deve-se considerar também o papel regulatório do Estado, sempre preponderante, em estabelecer a "legislação preventiva e corretiva" (SILVEIRA, 2004). Bem como da responsabilidade social do Estado em propiciar o efetivo diálogo entre os diferentes atores envolvidos no processo de licenciamento, cujo acesso à informação ambiental organizada e responsável, é peça fundamental. A questão do acesso à informação como requisito básico para a promoção da cidadania e para a formação de uma "consciência ambiental" visando reverter o caminho da degradação ambiental no Planeta, não é assunto novo e considerado aqui como um consenso, uma luta coletiva já sedimentada em prol da educação e para o meio ambiente (QUINTAS, 2004; JACOBI, 2003, 2005; PIRANHA \& CARNEIRO, 2009; LOUREIRO, 2010).

A “caixa-preta" do processo de licenciamento ambiental somente será aberta de fato quando o assunto se tornar objeto de ampla crítica pela sociedade e por isso, romper o campo restrito de domínio e controle das informações ambientais. O que requereria a divulgação de informações pelo órgão ambiental de dados e procedimentos sobre o licenciamento, em formato didático e acessível a todos, pois, o órgão ambiental não pode abster-se de sua responsabilidade educativa perante a sociedade. Os principais atores envolvidos no processo de licenciamento ambiental são: o setor público representado pelo órgão ambiental, o setor privado representado pelo minerador e consultoria ambiental por ele contratada, a sociedade em geral e aqueles diretamente afetados pela instalação e funcionamento de determinado empreendimento minerário.

O processo de licenciamento ambiental do setor de mineração possui características legais, histórico-culturais, econômicas e geológicas atreladas a cada Estado, a cada território no Brasil. O processo de licenciamento é de conhecimento restrito de profissionais que trabalham ou que realizam pesquisas diretamente sobre o tema. Grande parte da população, inclusive estudantes do ensino superior, e principalmente àqueles diretamente afetados pela instalação de um empreendimento minerário desconhecem a sua forma de operação básica.

Inspirado em aspectos educacionais e de cidadania voltados ao meio ambiente, portanto, este artigo tem por objetivo caracterizar o processo de licenciamento ambiental do setor de mineração em Goiás com identificação de seus principais problemas. A pesquisa realizada caracteriza-se como uma "pesquisa exploratória", cujo objetivo no entender de Carmo \& Ferreira (1998, p.47) procede ao "reconhecimento de uma dada realidade pouco ou deficientemente estudada e levantar hipóteses de entendimento dessa realidade". A caracterização do processo de licenciamento aqui realizada compreendeu pesquisa bibliográfica, análise e correlação de dados sobre o licenciamento do setor de mineração junto ao órgão ambiental de Goiás, período entre 2011-2014. Revisão da legislação ambiental federal e estadual pertinente ao tema, e de relatórios e estatísticas junto ao DNPM Departamento Nacional de Produção Mineral (recentemente denominado ANM - Agência Nacional de Mineração). Também foram utilizadas informações empíricas preexistentes caracterizadas por vistorias técnicas em campo, realizadas pelo autor deste trabalho, para fins de licenciamento ambiental do setor de mineração em Goiás, a partir do ano de 2011. 
A proposta deste artigo emerge da iminente necessidade de melhoria do licenciamento ambiental realizado em Goiás e tem como propósito incentivar o debate sobre o tema. Além de revelar determinadas carências gerais vinculadas ao processo de licenciamento do setor mineral goiano, a reflexão empreendida torna explícito alguns problemas específicos que podem servir como rotas de possíveis soluções.

\section{Características da mineração em Goiás}

O Estado de Goiás encontra-se bem posicionado no cenário da mineração brasileira. A participação de Goiás na produção mineral é de 4,2\%, atrás de Minas Gerais $(46,9 \%)$ e Pará (29,6\%), e seguido por São Paulo (4,0\%) e Bahia (2,6\%), Mato Grosso do Sul $(1,9 \%)$ e Mato Grosso (1,1\%). Os demais Estados em conjunto participaram com 9,8\% da arrecadação, tendo por base a CFEM - Compensação Financeira por Exploração Mineral (DNPM 2015a). A Tabela 1 apresenta um quadro das substâncias com maior demanda para pesquisa mineral junto ao DNPM, cujos relatórios encontram-se aprovados e um quantitativo de Títulos de Lavra vigentes.

Tabela 1: Principais substâncias minerais com relatórios de pesquisa mineral, aprovados junto ao DNPM em Goiás em 2014 e Títulos de Lavra.

\begin{tabular}{|c|c|c|c|c|c|c|c|}
\hline \multicolumn{4}{|c|}{ TÍTULOS DE LAVRA VIGENTES } & \multicolumn{4}{|c|}{ RELATÓRIOS DE PESQUISA APROVADOS } \\
\hline Substância & Posição & $\begin{array}{c}\text { Títulos } \\
\text { de Lavra }\end{array}$ & $\begin{array}{c}\text { Participação } \\
(\%)\end{array}$ & Substância & Posição & $\begin{array}{c}\text { Relatórios } \\
\text { Pesquisa } \\
\text { Aprovados }\end{array}$ & $\begin{array}{c}\text { Participação } \\
(\%)\end{array}$ \\
\hline Areia & 1 & 790 & 43,91 & Areia & 1 & 113 & 57,65 \\
\hline Argila & 2 & 243 & 13,51 & Calcário & 2 & 22 & 11,22 \\
\hline Calcário & 3 & 144 & 8,00 & Cascalho & 3 & 21 & 10,71 \\
\hline Cascalho & 4 & 141 & 7,84 & Granito & 4 & 6 & 3,06 \\
\hline Esmeralda & 5 & 64 & 3,56 & Níquel & 5 & 6 & 3,06 \\
\hline Amianto & 6 & 59 & 3,28 & Argila & 6 & 5 & 2,55 \\
\hline Água mineral & 7 & 52 & 2,89 & Quartzito & 7 & 4 & 2,04 \\
\hline Níquel & 8 & 45 & 2,50 & Basalto & 8 & 3 & 1,53 \\
\hline Granito & 9 & 36 & 2,00 & Ouro & 9 & 3 & 1,53 \\
\hline Ouro & 10 & 28 & 1,56 & Água termal & 10 & 2 & 1,02 \\
\hline Quartzito & 11 & 28 & 1,56 & Manganês & 11 & 2 & 1,02 \\
\hline Basalto & 12 & 27 & 1,50 & Xisto & 12 & 2 & 1,02 \\
\hline Titânio & 13 & 19 & 1,06 & Alumínio & 13 & 1 & 0,51 \\
\hline Xisto & 14 & 14 & 0,78 & Caulim & 14 & 1 & 0,51 \\
\hline Diamante & 15 & 12 & 0,67 & SUBTOTAL & 14 & 191 & 97,45 \\
\hline Filito & 16 & 9 & 0,50 & OUTROS & 5 & 5 & 2,55 \\
\hline Manganês & 17 & 9 & 0,50 & TOTAL & 19 & 196 & 100,00 \\
\hline Água termal & 18 & 7 & 0,39 & & & & \\
\hline SUBTOTAL & 18 & 1.727 & 96,00 & & & & \\
\hline OUTROS & 39 & 72 & 4 & & & & \\
\hline TOTAL & 57 & 1.799 & 100,00 & & & & \\
\hline
\end{tabular}

A pesquisa mineral é a primeira e mais importante etapa do empreendimento minerário, visa a comprovação da existência de recursos minerais. Em seu Art. 14 o 
Código de Mineração (Decreto-lei n 227/1967) aponta a pesquisa mineral como “a execução dos trabalhos necessários à definição da jazida, sua avaliação e a determinação da exequibilidade do seu aproveitamento econômico". De forma geral é após aprovação do relatório de pesquisa junto ao DNPM que tem início o processo de licenciamento junto ao órgão ambiental. A licença ambiental é uma exigência do DNPM, órgão responsável pela autorização da exploração mineral do subsolo no Brasil.

Uma comparação entre as Tabelas 1 e 2 (a seguir) indica que a demanda de processos de licenciamento ambiental do setor de mineração junto ao órgão ambiental de Goiás é um reflexo da demanda junto ao DNPM. Com maior volume de processos para quatro substâncias minerais: areia, cascalho, argila e calcário. Juntamente com granitos e basaltos utilizados para produção de brita ("extração de pedra"), em maior ou menor grau, tais substâncias possuem uso direto na construção civil ou com destinação para o mercado de agregados com amplo uso em projetos de pavimentação de estradas em Goiás, por exemplo.

Tabela 2: Quantidade de processos de licenciamento ambiental do setor de mineração instruídos junto ao órgão ambiental de Goiás (SECIMA), período entre 2011-2014.

\begin{tabular}{l|c|c|c|c}
\multicolumn{1}{c}{ Atividade / Substância mineral } & \multicolumn{3}{c}{ Ano / N ${ }^{\circ}$ Processos } \\
\cline { 2 - 5 } Extração de areia & $\mathbf{2 0 1 1}$ & $\mathbf{2 0 1 2}$ & $\mathbf{2 0 1 3}$ & $\mathbf{2 0 1 4}$ \\
\hline Extração de cascalho & 301 & 227 & 283 & 234 \\
\hline Extração de argila & 51 & 58 & 119 & 78 \\
\hline Extração de areia e cascalho & 125 & 109 & 105 & 105 \\
\hline Extração de calcário & 97 & 50 & 102 & 121 \\
\hline Extração de pedra & 37 & 33 & 36 & 35 \\
\hline Extração de rocha ornamental & 13 & 9 & 9 & 16 \\
\hline Extração de gemas & 5 & 3 & 8 & 6 \\
\hline Extração de filito & 3 & 7 & 5 & 6 \\
\hline Extração de pedra sabão & 2 & 3 & 1 & 2 \\
\hline Extração de seixo rolado & 0 & 0 & 1 & 1 \\
\hline Extração de minerais não-metálicos & 0 & 0 & 0 & 0 \\
\hline Extração e beneficiamento de minerais não-metálicos & 2 & 16 & 21 & 21 \\
\hline Extração de outros materiais não-metálicos & 15 & 13 & 24 & 15 \\
\hline Extração de minerais metálicos & 40 & 22 & 47 & 32 \\
\hline & 23 & 46 & 51 & 45 \\
\hline Eon & $\mathbf{7 1 4}$ & $\mathbf{5 9 6}$ & $\mathbf{8 1 2}$ & $\mathbf{7 1 7}$ \\
\hline
\end{tabular}

Fonte: Araújo (2017, p.78) - dados aproximados Semarh, Jan/2015.

Para o licenciamento ambiental o empreendedor deverá comprovar junto ao órgão ambiental o direito de titularidade para extração mineral, fornecido pelo DNPM, e compatível com o regime de extração minerária em que se encontre naquele órgão, para solicitação da licença ambiental desejada. O DNPM, por outro lado, somente autorizará 
a denominada Concessão de Lavra (que é uma categoria de Título de Lavra) após a emissão da licença de instalação pelo órgão ambiental e, sua respectiva apresentação junto ao DNPM. Após a publicação da Portaria de Lavra, o minerador solicita a licença de funcionamento junto ao órgão ambiental, para análise e aprovação. $\mathrm{Na}$ fase de autorização de pesquisa o órgão ambiental não emite licenças ambientais, a exceção da comprovação de solicitação da Guia de Utilização (GU) junto ao DNPM. Convém destacar, no âmbito do licenciamento, que a GU é documento emitido pelo DNPM e que admite, em caráter "excepcional", a extração de substâncias minerais em área titulada, antes da outorga da Concessão de Lavra, como indica a Portaria DNPM 144/2007 (Art. $2^{\circ}$ ). De acordo com DNPM (2015b) "Títulos de Lavra", refere-se a todo o diploma que autoriza a extração de um determinado bem mineral, sendo subdividido da seguinte maneira: Concessão de Lavra (Manifesto de Mina, Decreto de Lavra, Portaria de Lavra), Registro de Extração, Permissão de Lavra Garimpeira e Guia de Utilização. Em síntese, a Figura 1 mostra a correlação entre DNPM e órgão ambiental.

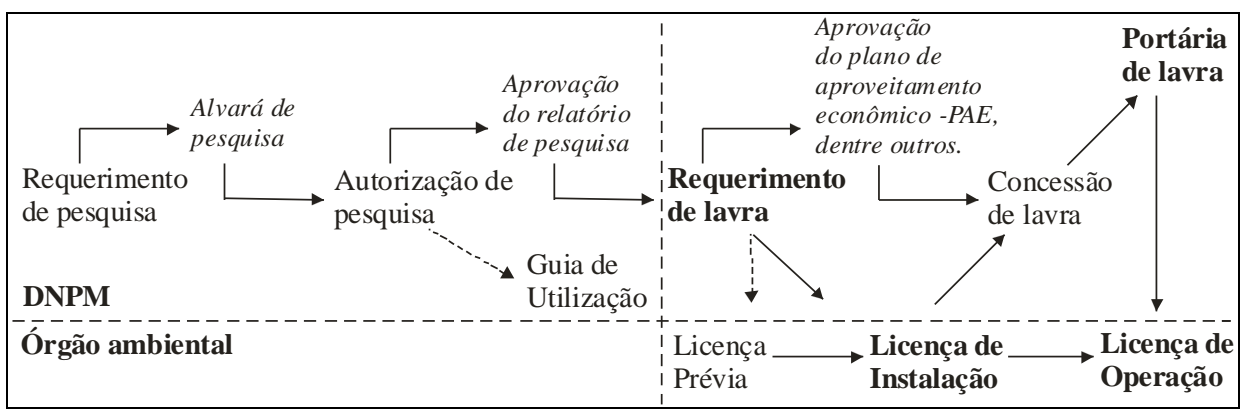

Figura 1: Correlação geral entre DNPM e órgão ambiental.

Fonte: Esquematizado a partir da Resolução Conama 09/90. Araújo (2017, p. 62).

Importante notar aqui, a explícita carência de "diálogo" e correlação das informações entre o DNPM goiano e o órgão ambiental de Goiás. Especialmente com relação a um acordo de opiniões para o uso de terminologia e categorização adequada das substâncias minerais para o licenciamento, como se pode observar pela Tabela 2. Por exemplo, o uso do termo "extração de pedra" que, dentre outros aspectos, impossibilita o reconhecimento do tipo de substância mineral de que trata a atividade a ser licenciada. Cita-se também a não distinção entre as atividades de extração de areia "em leito de rio" e extração de areia "em cava", ou mesmo a consideração de uma categoria demasiado geral como a dos "minerais metálicos" (ouro, níquel, manganês, bauxita, etc) para instrução e abertura de processos de licenciamento. Tendo em vista que na área ambiental, ao refletir sobre a mineração e meio ambiente, deve-se considerar para cada substância mineral, que ela possui a sua forma específica de ocorrência na natureza e condicionada por processos geológicos característicos. E que, para pesquisa e exploração pelo ser humano, porventura também ocasionam distintos impactos ambientais e em escalas diversas. 


\section{Impactos ambientais da mineração}

Em sua maior parte, senão toda atividade de mineração causa algum tipo de impacto ambiental ao meio ambiente. Atrelado ao crescimento da produção mineral, também caminham juntos (ou deveriam caminhar juntos), o impacto ambiental e a recuperação das áreas degradadas. Por assim dizer, "duas faces da mesma moeda". A prática do licenciamento ambiental tem mostrado que, malgrado o avanço do impacto ambiental, a recuperação das áreas degradadas pela mineração dificilmente tem evoluído da etapa de projeto (BITAR, 1997).

Geralmente, o impacto ambiental da atividade minerária caracteriza-se por maior densidade e menor extensão quando comparado a outras atividades como a agricultura e a pecuária, atividades bem desenvolvidas em Goiás. Importante destacar, que tais atividades, também concorrem com a atividade minerária para a degradação histórica das matas ciliares que margeiam os rios e mananciais goianos.

Em Goiás, a exploração mineral com mina subterrânea encontra-se restrita à exploração de minerais metálicos, como a extração de ouro, por exemplo. E, geralmente vinculada a empreendimentos de potencial médio a grande porte, considerando a necessidade de maiores investimentos econômicos desde a fase de pesquisa. Dentre outros aspectos, com objetivo de medição da reserva mineral e estudo de viabilidade técnico-econômica e ambiental de exploração para implantação do empreendimento.

Comparado à lavra subterrânea, geralmente, o método de lavra a céu aberto resulta em maiores impactos ambientais, tanto pela intervenção em área de maior extensão quanto pela movimentação de maior volume de material (MACEDO et al. 2001). Porém, em ambos os casos a atenção para a geração de impactos ambientais se desloca principalmente para as áreas de disposição de material estéril, de rejeitos e sistema de beneficiamento utilizado, cuja barragem de disposição de rejeitos a exemplo da mineração de ouro, em muitos casos possui insumos químicos envolvidos e com alto poder de poluição. Devido à rigidez locacional da jazida, o impacto ambiental na área de lavra a céu aberto é quase sempre "inevitável" em sua prática. Ver Figura 2.

A supressão da cobertura vegetal é inerente à instalação da atividade minerária a céu aberto. Projetos ambientais para o setor de mineração, desde a sua concepção devem prever a solicitação de licença ambiental específica junto ao órgão ambiental para "retirada da vegetação" (e solo). A Figura 2, por exemplo, mostra dois casos típicos de áreas de lavra e degradação ambiental gerada pela atividade minerária em Goiás: Em (A) extração de granito para produção de rocha ornamental e (B) extração de calcário para produção de corretivo de solo para indústria agrícola. Neste último caso, a mineração ocorre em área de potencial espeleológico, de ocorrência de cavidades subterrâneas como é mostrado em (C). A apresentação de "estudo espeleológico" para áreas de potencial espeleológico é uma exigência para o licenciamento ambiental, cujas diretrizes básicas para a proteção do patrimônio espeleológico encontram-se descritas pela Resolução do Conama n 347/2004. 


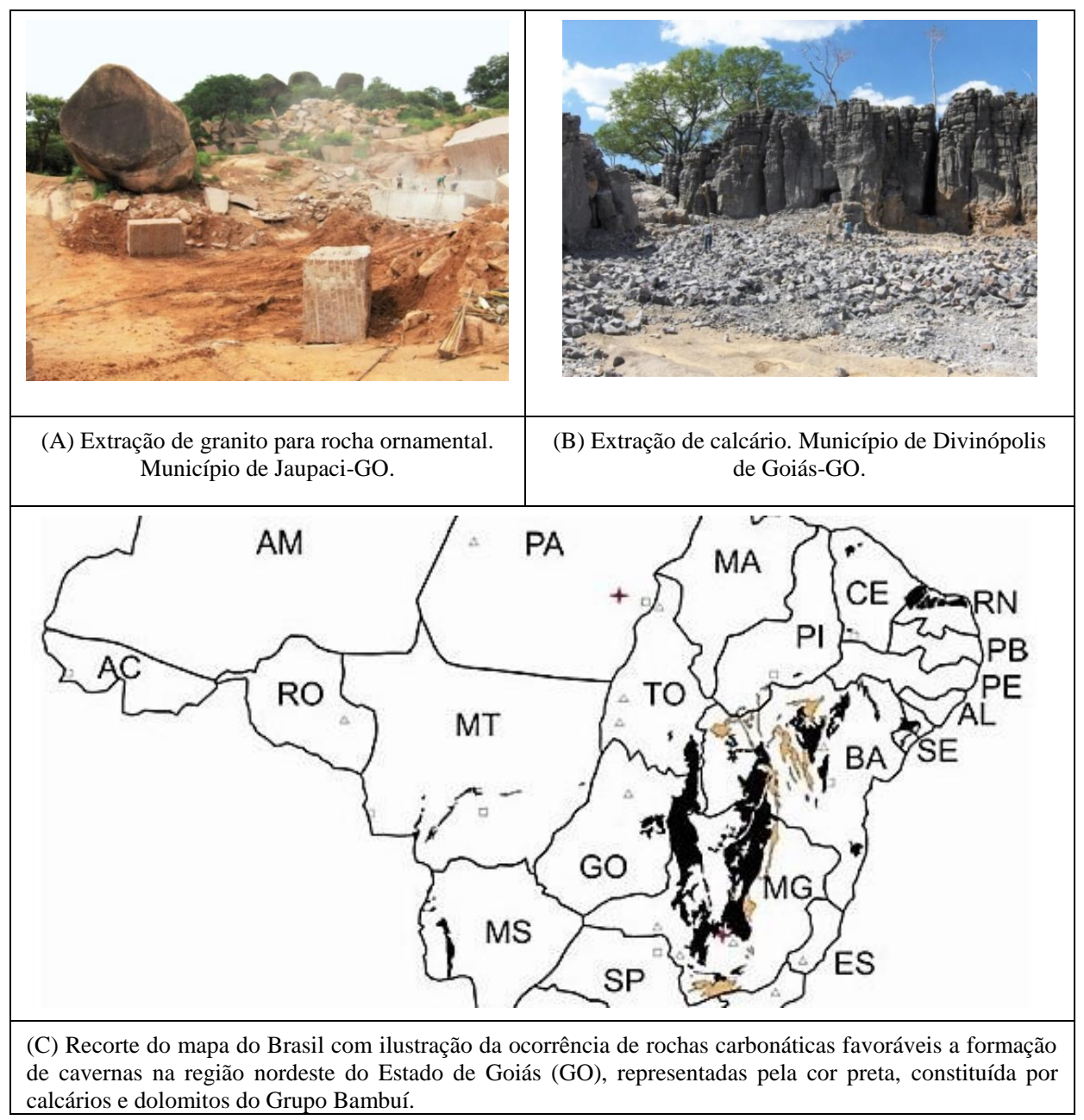

Figura 2: Paisagens da extração de granito e calcário em Goiás

Fonte: Acervo do autor (A e B). Em C mapa extraído de CECAV (2013).

A mineração a céu aberto constitui a grande maioria das atividades licenciadas em Goiás e envolve as mais variadas substâncias minerais. Neste âmbito, distinguem-se aqui três casos gerais ao tratar da relação entre impacto ambiental da atividade minerária e recuperação das áreas degradadas, a exemplo da sintética e didática descrição dada por Fonseca (1995, p. 178) e apontadas a seguir. Note-se aqui, um marcante relato daquele autor, "a mineração desmancha o morro, e fica no lugar um buraco". Na prática, esta é uma circunstância observada com frequência.

- Áreas e jazidas onde é possível a volta a uma situação igual, ou muito próxima, à anterior da existência da mina; 
- Áreas e jazidas onde a mineração altera irreversivelmente a paisagem e não é possível a volta a situação anterior;

- Áreas e jazidas onde, a critério da sociedade e/ou das autoridades, existem outras razões que recomendem que a mineração não se implante.

No que tange as substâncias minerais com maior demanda para o licenciamento ambiental em Goiás e que geralmente são de uso direto na construção civil, cita-se aqui a extração de areia, observa-se o seguinte cenário indicado pelo Gráfico 1.

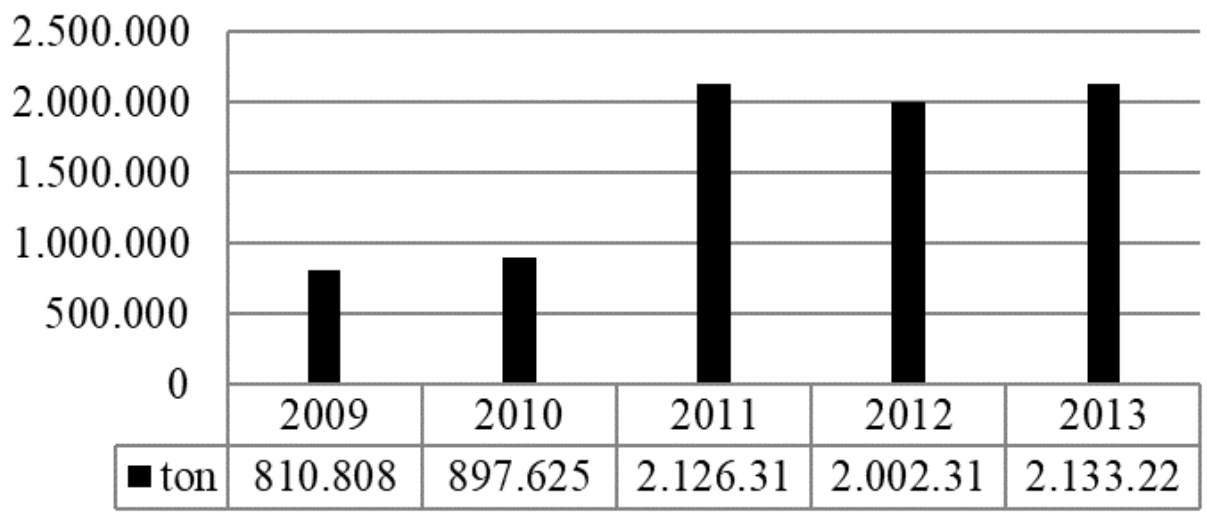

Figura 3: Evolução da produção de areia em Goiás 2009-2013.

Fonte: Dados extraídos DNPM (2015 b). Araújo (2017, p. 39).

Note-se pelo referido gráfico, entre os anos de 2010 e 2011 a produção de areia mais que dobrou no Estado de Goiás para a extração de areia, mantendo-se estável até 2013, período aqui considerado. Neste âmbito, o cenário vislumbrado é que juntamente com o aumento da produção de areia houve também o aumento do impacto ambiental ocasionado pela mineração de areia em suas mais variadas formas de exploração.

Dentre os métodos de lavra mais utilizados para extração de areia em Goiás, cita-se a dragagem de sedimentos em leito de rio e a lavra a céu aberto (ou em cava). Neste último caso, é comum no território goiano a exploração de quartzito para produção de areia. Em Goiás, é frequente a ocorrência de rochas quartzíticas friáveis cujo desmonte da rocha torna-se relativamente fácil de forma mecânica, não sendo necessária em muitos casos a remoção por explosivos. O beneficiamento é composto por etapas de moagem e lavagem do material extraído em bacias de decantação, visando, pois, a separação da areia de interesse econômico da porção de material fino que compõe a rocha, formando um rejeito de lama. Dado o contexto geológico local, há formação de cava inundada, cuja exploração atingiu o "lençol freático" ou superfície do nível d'água subterrânea. A inundação da cava de exploração caracteriza um impacto ambiental que inviabiliza ou mesmo dificulta demasiadamente um caminho técnico e economicamente viável para a recuperação da área degradada pela mineração de areia. Nestes locais, além 
da intensa alteração da paisagem, a alteração do regime natural das águas superficiais e subterrâneas também é um dos impactos ambientais potenciais, e que carecem de maiores estudos e diagnósticos ambientais de detalhe. Principalmente devido à ausência de instrumentos legais específicos para o setor de extração de areia em Goiás, visando, pois, normatizar e garantir determinada isonomia para exigências técnicas vinculadas ao projeto ambiental, desde a sua fase inicial de instrução junto ao órgão ambiental para o licenciamento.

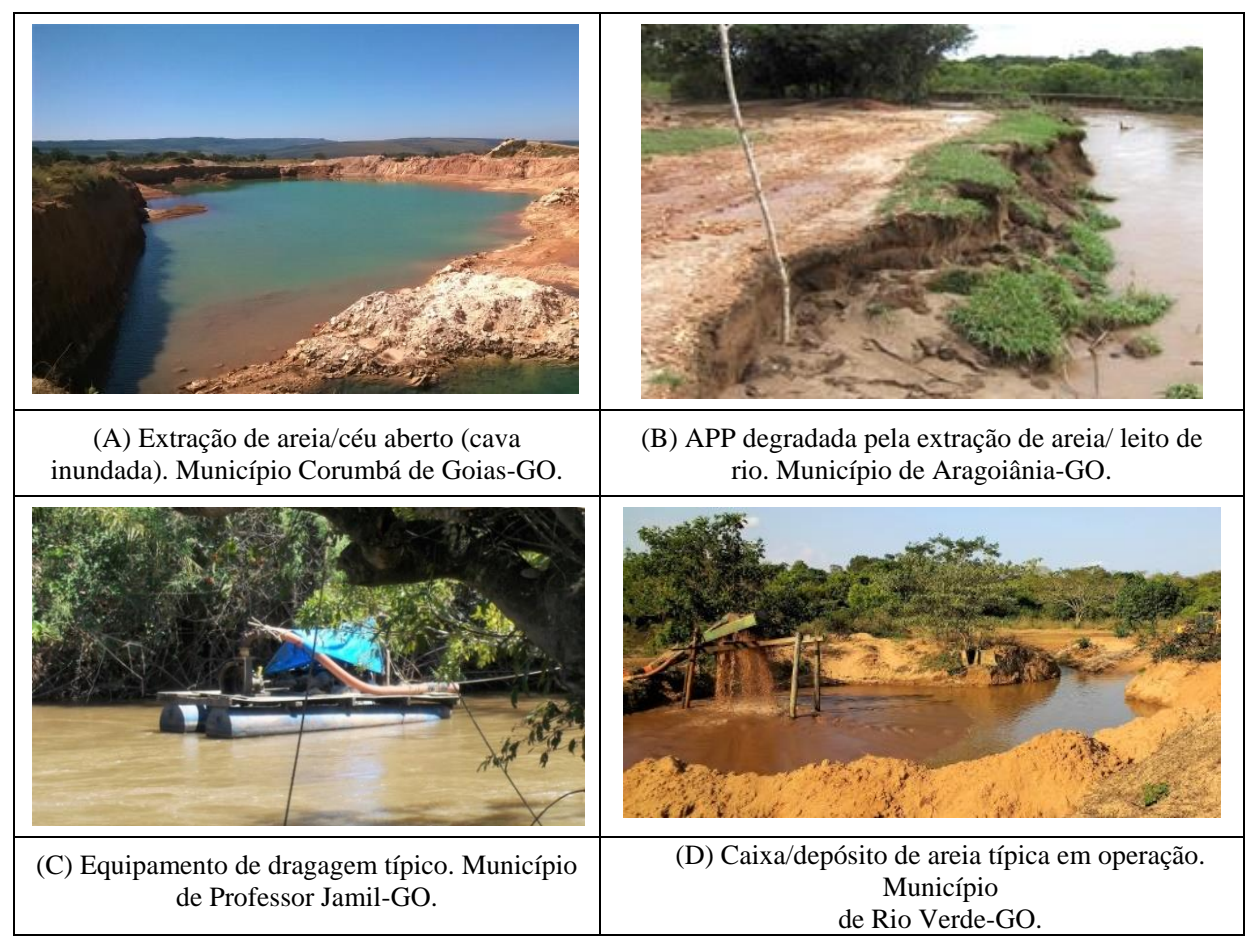

Figura 4: Paisagens da extração de areia em Goiás Fonte: Acervo do autor (A, B, C, D).

A extração de quartzito para produção de areia, geralmente ocorre em regiões de geomorfologia acidentada e composta por terrenos arenosos, com pouca viabilidade para instalação efetiva de outras atividades econômicas como a agricultura e pecuária. A Figura 3-A, por exemplo, mostra um cenário clássico do impacto ambiental da extração de quartzito para produção de areia em Goiás, com formação de cava inundada. Neste caso, o tamanho da cava em área aproxima-se às dimensões de um campo de futebol. Por outro lado, na Figura 3-B tem-se um exemplo de Área de Preservação Permanente (APP) degradada pela atividade de extração de areia em leito de rio, cujo método de exploração ainda é muito comum em Goiás. Deve-se ter em mente que, muitos rios, além de sua potencialidade para exploração mineral, são fontes de abastecimento de água para o 
consumo humano, para a dessedentação de animais, irrigação para a agricultura e abastecimento de variados setores da indústria goiana.

$\mathrm{Na}$ Figura 3-C tem-se o exemplar de um equipamento de dragagem típico, ancorado em leito de rio, constituído por uma barcaça rudimentar, geralmente com um motor a diesel adaptado (por exemplo, de um caminhão) e que suga sedimentos de fundo, que podem ser areia, cascalho e matéria orgânica (polpa), direcionando-os por meio de canalização também adaptada a cada circunstância, para local da margem do rio denominado "caixa de areia" (depósito), onde é realizada uma "peneira" para separação da areia, cascalho e matéria orgânica. Assim, na Figura 3-D é mostrado o exemplo de uma caixa de areia em operação, situada na margem do rio. Caixas/depósitos de areia devem estar localizados fora da Área de Preservação Permanente.

A APP é variável de acordo com a largura do rio. Segundo o "novo código florestal", a Lei $n^{\circ} 12.651 / 2012$ define APP em seu Art. 3º, como "área protegida, coberta ou não por vegetação nativa, com a função ambiental de preservar recursos hídricos, a paisagem, a estabilidade geológica e a biodiversidade, facilitar o fluxo gênico de fauna e flora, proteger o solo e assegurar o bem-estar das populações humanas" (BRASIL, 2012). Ver Tabela 3 as delimitações da APP de um curso d'água.

Tabela 3: Dimensões da APP de acordo com Art. $4^{\circ}$ da Lei 12.651/12.

\begin{tabular}{c|c}
\hline Largura do curso d'água & Largura da APP \\
\hline Até 10 metros & 30 metros \\
\hline Entre 10 e 50 metros & 50 metros \\
\hline Entre 50 e 200 metros & 100 metros \\
\hline Entre 200 e 600 metros & 200 metros \\
\hline Acima de 600 metros & 500 metros \\
\hline
\end{tabular}

Fonte: BRASIL, 2012

\section{Aspectos legais do processo de licenciamento}

Cada atividade de licenciamento possui um regramento específico, uma legislação ambiental que a comporta. A hierarquia geral e caminhamento para aspectos legais mais restritivos, ou seja, "daquilo que se pode ou não pode fazer", encontra-se representado pela legislação federal, estadual e municipal, respectivamente. Vinculado diretamente aos interesses do licenciamento ambiental do setor mineral, destacam-se três princípios gerais e orientadores descritos pelo Art. 225 da Constituição Federal de 1988 em seu Capítulo VI que trata "do meio ambiente", quais sejam: "IV - exigir, na forma da lei, para instalação de obra ou atividade potencialmente causadora de significativa degradação ao meio ambiente, estudo prévio de impacto ambiental, a que se dará publicidade"; "VI - promover a educação ambiental em todos os níveis de ensino e a conscientização pública para a preservação do meio ambiente"; e "§2० - aquele que explorar recursos minerais fica obrigado a recuperar o meio ambiente degradado, de acordo com a solução técnica exigida pelo órgão público competente, na forma da lei” (BRASIL 1988, grifo nosso). 
Em regra, o licenciamento ambiental no Brasil é realizado pelos Estados, considerando o disposto na Política Nacional de Meio Ambiente (PNMA), Lei 6.938/81, pelo Conama, especialmente as Resoluções $n^{\circ} 01 / 86$ e $n^{\circ} 237 / 97$ e, pela Lei Complementar $n^{\circ} 140$, de 8 de dezembro de 2011, que veio a disciplinar a cooperação entre a União, Estados e Municípios.

A licença ambiental é o produto final do processo de licenciamento, "um ato administrativo pelo qual o órgão ambiental competente estabelece condições, restrições e medidas de controle ambiental que deverão ser obedecidas pelo empreendedor [...]", para o exercício legal do empreendimento ou atividade, como apresenta a Resolução do Conama $n^{\circ} 237 / 97$ e que também define os procedimentos gerais para o licenciamento ambiental em seu Art. $10^{\circ}$ (I-VIII). A Figura 4 mostra de forma esquemática uma síntese do procedimento geral do licenciamento e aplicável a todas as atividades.

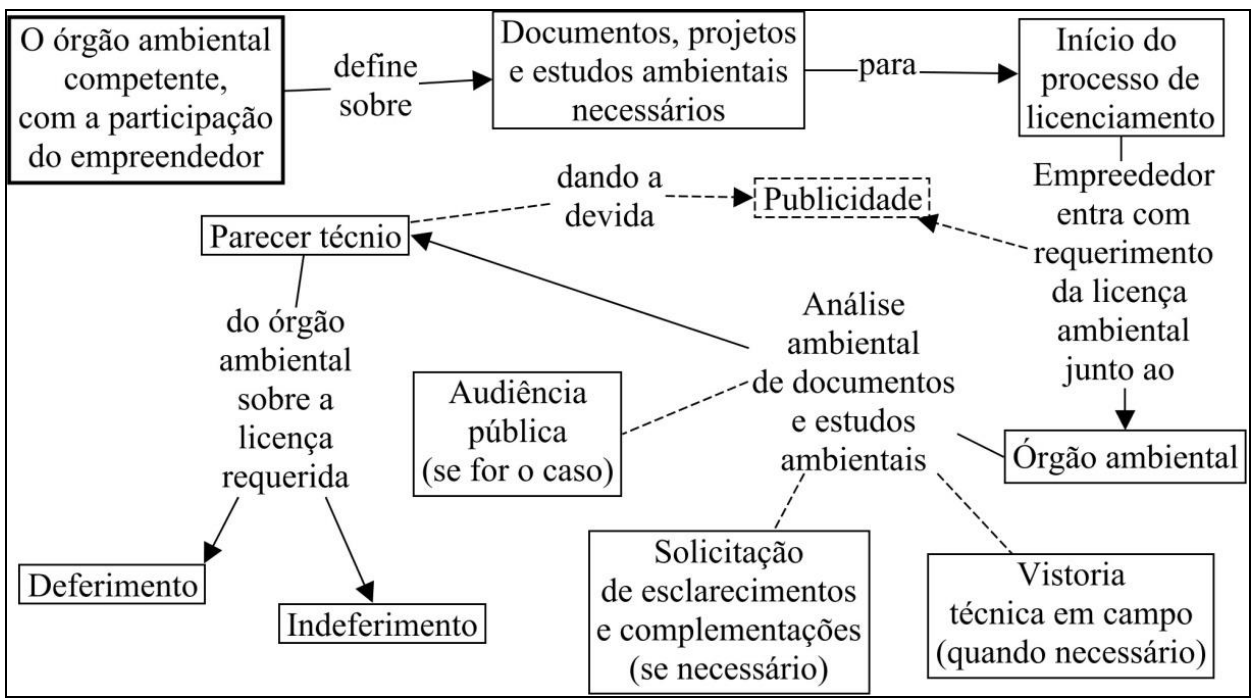

Figura 5: Procedimento geral de licenciamento, Resolução Conama ${ }^{\circ}{ }^{\circ} 237 / 97$.

Fonte: Modificado de Araújo (2017, p.59).

Três tipos de licenças ambientais poderão ser emitidos pelo poder público, órgão ambiental competente, durante o processo de licenciamento, segundo a própria Resolução do Conama n 237/97 e, como indica o Decreto 99.274/90 (art.19º), que regulamenta a PNMA:

I - Licença Prévia (LP), na fase preliminar do planejamento de atividade, contendo requisitos básicos a serem atendidos nas fases de localização, instalação e operação, observados os planos municipais, estaduais ou federais de uso do solo;

II - Licença de Instalação (LI), autorizando o início da implantação, de acordo com as especificações constantes do Projeto Executivo aprovado; 
III - Licença de Operação (LO), autorizando, após as verificações necessárias, o início da atividade licenciada e o funcionamento de seus equipamentos de controle de poluição, de acordo com o previsto nas Licenças, Prévia e de Instalação. (BRASIL, 1990, grifo nosso).

Um problema recorrente na prática do licenciamento ambiental e que diz respeito à tomada de decisões, principalmente para o setor mineral, envolve a caracterização de impacto ambiental, regional ou local, e consequente classificação das atividades minerárias e estabelecimento de regras para o licenciamento ambiental. A Figura 5 mostra a lista das atividades do setor de mineração sujeitas ao licenciamento e de acordo com a Resolução n $237 / 97$.

Extração e tratamento de minerais

ANEXO I - Resolução Conama n ${ }^{\circ} 237 / 97$

- $\quad$ pesquisa mineral com guia de utilização

- lavra a céu aberto, inclusive de aluvião, com ou sem beneficiamento

- lavra subterrânea com ou sem beneficiamento

- lavra garimpeira

- $\quad$ perfuração de poços e produção de petróleo e gás natural

Indústria de produtos minerais não metálicos

- $\quad$ beneficiamento de minerais não metálicos, não associados à extração

- fabricação e elaboração de produtos minerais não metálicos tais como: produção de material cerâmico, cimento, gesso, amianto e vidro, entre outros.

Figura 6: Atividades do setor de mineração sujeitas ao licenciamento

Fonte: Extraído e adaptado da Resolução Conama n 237/97. Araújo (2017, p.56)

Estabelecer o vínculo entre determinada atividade minerária e a caracterização de seu potencial impacto ao meio ambiente é uma questão-chave, situada no momento inicial do processo de licenciamento. Diz respeito a dois aspectos principais: ao procedimento de instrução do processo de licenciamento junto ao órgão ambiental (abertura do processo) e, ao próprio caminho da análise ambiental para obtenção da licença requerida (desenvolvimento do processo). Em síntese, determinada atividade de licenciamento ou substância mineral a ser licenciada, pode seguir dois caminhos básicos, quais sejam: o seu enquadramento dentro do processo de "licenciamento ambiental convencional" que, de acordo com Sanchez (2008) caracteriza-se como procedimento de análise de solicitação de licença ambiental que não requeira a apresentação de um estudo de impacto ambiental; ou, enquadramento da atividade como "atividade de significativo impacto". Neste caso, é realizado o licenciamento prévio com a apresentação de estudos ambientais denominados de EIA-RIMA (Estudo de Impacto Ambiental-Relatório de Impacto Ambiental). Sanchez (op cit., p.81) postula duas funções básicas para o licenciamento ambiental: "disciplinar e regulamentar o acesso aos recursos ambientais e sua utilização" e, "prevenir danos ambientais". 


\section{Sobre a classificação das atividades minerárias para o licenciamento}

O regramento do licenciamento ambiental da mineração em Goiás atualmente é dado pela Portaria Estadual Semarh 010/2010 (GOIÁS, 2010). Em síntese, tal legislação indica uma lista de documentos necessários para solicitação de LP, LI e LF (LO). É apresentado também um termo de referência geral de orientação para elaboração do projeto ambiental denominado de RCA-PCA (Relatório de Controle Ambiental e Plano de Controle Ambiental), bem como orientações básicas para elaboração de material cartográfico (mapas) associado ao projeto ambiental.

A publicação da Portaria 010/2010 foi inédita em sua época, pois não havia legislação estadual específica para o setor mineral em Goiás. Dentre os aspectos relevantes para a implantação de uma nova "cultura do licenciamento" promovida pela referida legislação, cita-se a promoção de determinado disciplinamento de análise da documentação - checklist, e padronização básica para a apresentação de projetos ambientais para o licenciamento junto ao órgão ambiental goiano para o caso de RCAPCA. Porém, a referida legislação não estabelece critérios para classificação de atividades e empreendimentos minerários para o licenciamento ambiental.

A existência de critérios legais específicos para classificação das atividades e empreendimentos minerários é um dos aspectos mais importantes vinculados ao licenciamento ambiental do setor de mineração. Tais critérios de classificação, dentre outros aspectos, servem para realizar uma adequação entre a atividade minerária a ser licenciada (substância mineral) e a categoria de projeto ambiental necessário para ser apresentado para a avaliação ambiental da atividade. Note-se aqui, o exemplo de classificação das atividades minerárias e critérios utilizados para o licenciamento pelo órgão ambiental do Estado de São Paulo, Companhia Ambiental do Estado de São Paulo (CETESB, 2014a; 2014b). Ver Figura 6.

De acordo com a referida figura, critérios assim estabelecidos tornam as decisões sobre o meio ambiente "mais técnica e menos política". Ou seja, tem por consequência positiva a "despolitização" do setor técnico do licenciamento ambiental. Desta forma, o analista ambiental tende a fundamentar as suas decisões sobre o meio ambiente com mais objetividade e segurança. E, por isso com descrição de orientações mais claras acerca daquilo que "se pode ou não pode fazer", principalmente na fase inicial de instrução e abertura do processo de licenciamento ambiental. 


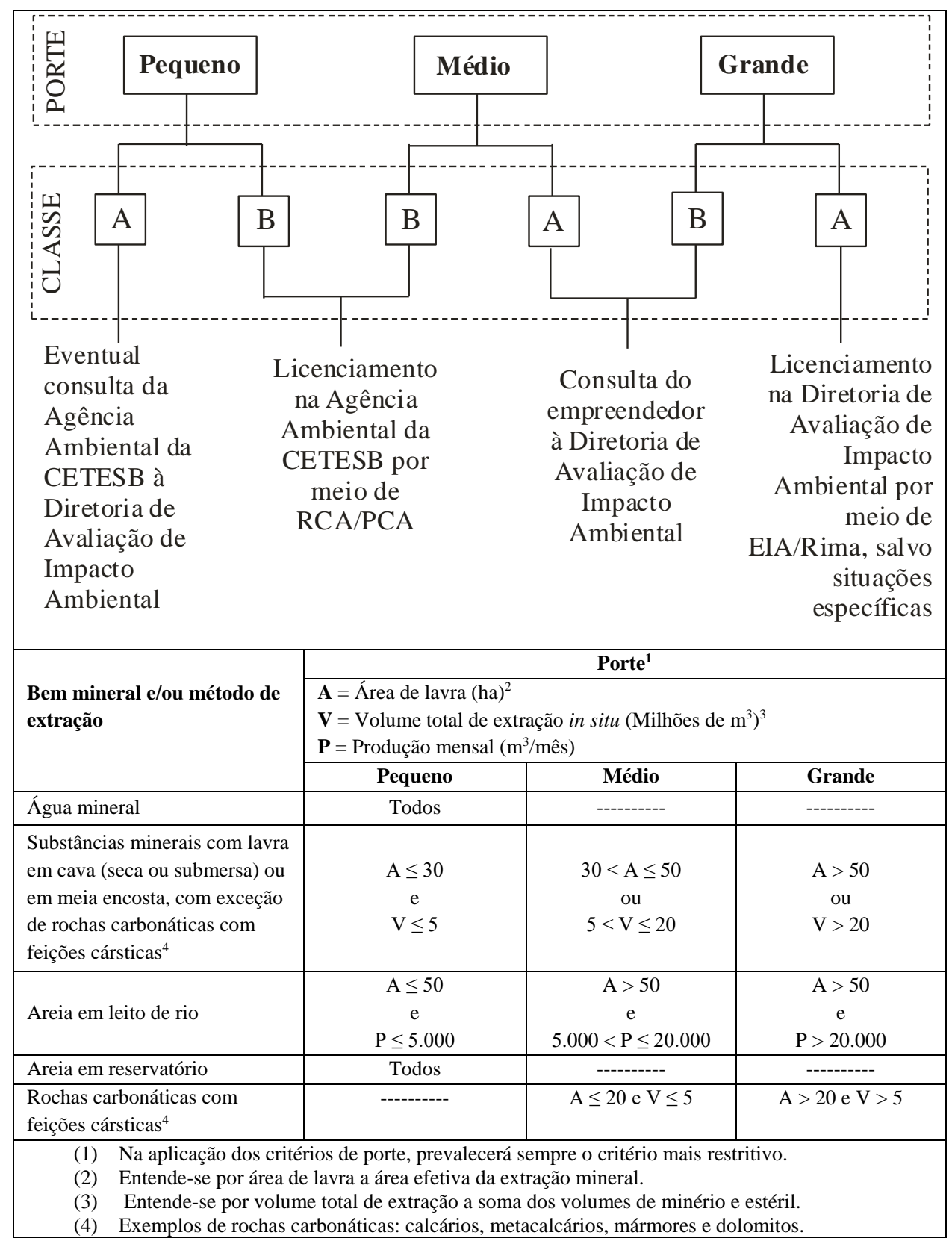

Figura 7: Exemplo de classificação de empreendimento minerários CETESB-SP

Fonte: Adaptado de CETESB (2014a). Araújo (2017, p.91). 
Por outro lado, o próprio minerador e consultoria ambiental por ele contratada, quando em posse das informações da jazida previamente autorizada pelo DNPM e de um quadro de classificação das atividades minerárias previamente estabelecido para o licenciamento como mostra referida figura, tais aspectos proporcionariam o diálogo com o órgão ambiental também mais objetivo para elaboração do projeto ambiental necessário. $\mathrm{E}$, portanto, tornando os procedimentos mais rápidos e justos para todos os envolvidos, sobretudo para a própria consultoria responsável pela elaboração do projeto ambiental, que, de antemão já teria plena consciência do porte do empreendimento minerário. Por exemplo, para o caso dos critérios estabelecidos na Figura 6, sendo a atividade constituída de uma área de 20 hectares e o volume de extração de 10 milhões de metros cúbicos, a classificação da atividade seria definida sendo de "porte médio", haja vista que o critério mais restritivo prevalece. O que há de se fazer?

\section{Processo de licenciamento ambiental do setor de mineração em Goiás}

A ausência de critérios legais específicos para classificação das atividades e empreendimentos minerários em Goiás para tomada de decisões, assim, tem por principal consequência a condução de "quase todos" os processos de licenciamento ambiental do setor de mineração para o denominado "licenciamento convencional", o procedimento mais "rápido e barato" para obtenção da licença ambiental. Porém, nem sempre o caminho mais adequado para a avaliação ambiental da atividade a ser licenciada, e decisão sobre implantação de programas e monitoramento ambiental visando à manutenção do meio ambiente ecologicamente equilibrado, eis a questão.

Estudos ambientais do tipo EIA-RIMA são estudos que demandam maior tempo e recursos financeiros, tanto para a sua elaboração pela consultoria ambiental quanto para a sua análise pelo órgão ambiental. São necessárias equipes multidisciplinares e bem formadas. Não é raro o questionamento junto ao órgão ambiental sobre a adequação legal e decisão de enquadramento ambiental de determinada atividade mineral e seu estudo ambiental exigido. $\mathrm{O}$ cenário aponta que poucos empreendimentos terminam por fazer um estudo de impacto ambiental, um EIARIMA. Esta é uma triste realidade para o meio ambiente goiano e que pode ser visualizado pela Tabela 4 .

Os números revelam que são consideradas atividades de significativo impacto ambiental em Goiás, as atividades de extração de calcário, especialmente a extração de calcário vinculada à indústria de cimento, casos da extração de rochas ornamentais, e minerais metálicos em geral (ouro, níquel, bauxita, por exemplo). Pode-se dizer que tal "enquadramento das atividades" representa um vestígio da própria memória ambiental institucional e do modus operandi do licenciamento. Ou seja, representa um uso e costume, um modo de operação do licenciamento ambiental goiano e sedimentado em sua prática do dia a dia por gerações em décadas, haja vista a inexistência de critérios para o enquadramento das atividades para o licenciamento. Neste contexto, as 
solicitações de LP para atividades de extração de areia e argila indicados na referida tabela devem ser considerados "erros de instrução" do processo de licenciamento.

Tabela 4: Requerimentos de Licença Prévia setor de mineração em Goiás 2011-2014.

\begin{tabular}{|c|c|c|c|c|}
\hline \multirow{2}{*}{ Atividade } & \multicolumn{4}{|c|}{ Número de Processos / Ano } \\
\hline & 2011 & 2012 & 2013 & 2014 \\
\hline Extração de areia & 1 & & & \\
\hline Extração de argila & & & 1 & \\
\hline Extração de areia e cascalho & 1 & & & \\
\hline Extração de calcário & 5 & 2 & 1 & 1 \\
\hline Extração de rocha ornamental & & & & 1 \\
\hline Extração e beneficiamento de minerais não-metálicos & & 1 & & 2 \\
\hline Extração de minerais metálicos & 2 & 4 & 1 & 1 \\
\hline TOTAL & 9 & 7 & 3 & 5 \\
\hline
\end{tabular}

Fonte: Adaptado de Araújo (2017, p.65) - dados aproximados Semarh, Jan/2015.

A Tabela 4 demonstra que o denominado licenciamento "trifásico" caracterizado pela sequência de solicitação de licença prévia (LP), licença de instalação (LI) e licença de funcionamento (LF) junto ao órgão ambiental, restringe-se em sua maior parte aos minerais metálicos, ou mesmo, para um seleto tipo de minerais metálicos, extração de calcário (cimento) e casos isolados de minerais não metálicos.

O processo de licenciamento ambiental de atividades e empreendimentos minerários em Goiás, portanto, em sua grande maioria encontra-se vinculado ao "licenciamento convencional", representado pela solicitação direta das licenças de instalação (LI) e de funcionamento (LF), com apresentação de estudo ambiental denominado RCA-PCA e de acordo com a Portaria 010/2010. Estudos ambientais do tipo EIA-RIMA são apresentados somente para os casos de requerimento de licenciamento prévio (LP).

Mas, afinal, o que torna o licenciamento ambiental convencional tão atraente para o empreendedor do setor mineral goiano?

- No licenciamento convencional, a análise ambiental do processo é realizada por um único analista. Ele conduz sozinho todas as suas etapas (ver Figura 7). Após distribuição do processo para o "analista (A)", é realizada análise da documentação (Etapa I), em seguida análise teórica do projeto ambiental (Etapa II). É redigido um parecer de análise processual (Etapa III), caso necessário é exigido complementações de documentação e projeto por meio de notificação. Em seguida, realiza-se análise ambiental de campo (Etapa IV). É elaborado o relatório de vistoria (Etapa V). Caso necessário solicita-se novas adequações de projeto e estudos ambientais de detalhe. Atestada a viabilidade ambiental do empreendimento é elaborada a minuta de licença (Parecer sobre Licença) e elaboração das condicionantes de licença para a atividade licenciada (Etapa VI). 
- No licenciamento convencional não é realizada audiência pública, prevista somente para empreendimentos de significativo impacto ambiental, cuja instrução do processo de licenciamento passa pela solicitação de LP e apresentação de estudos ambientais do tipo EIA-RIMA.

- O licenciamento convencional é composto de duas fases, com requerimento direto das licenças de instalação e funcionamento (LI e LF) e apresentação de projeto tipo RCA-PCA.

- No licenciamento convencional não é exigida a realização de "compensação ambiental", nos termos da Resolução Conama n 371/2006, cujo procedimento encontra-se vinculado para atividades de significativo impacto ambiental (LP).

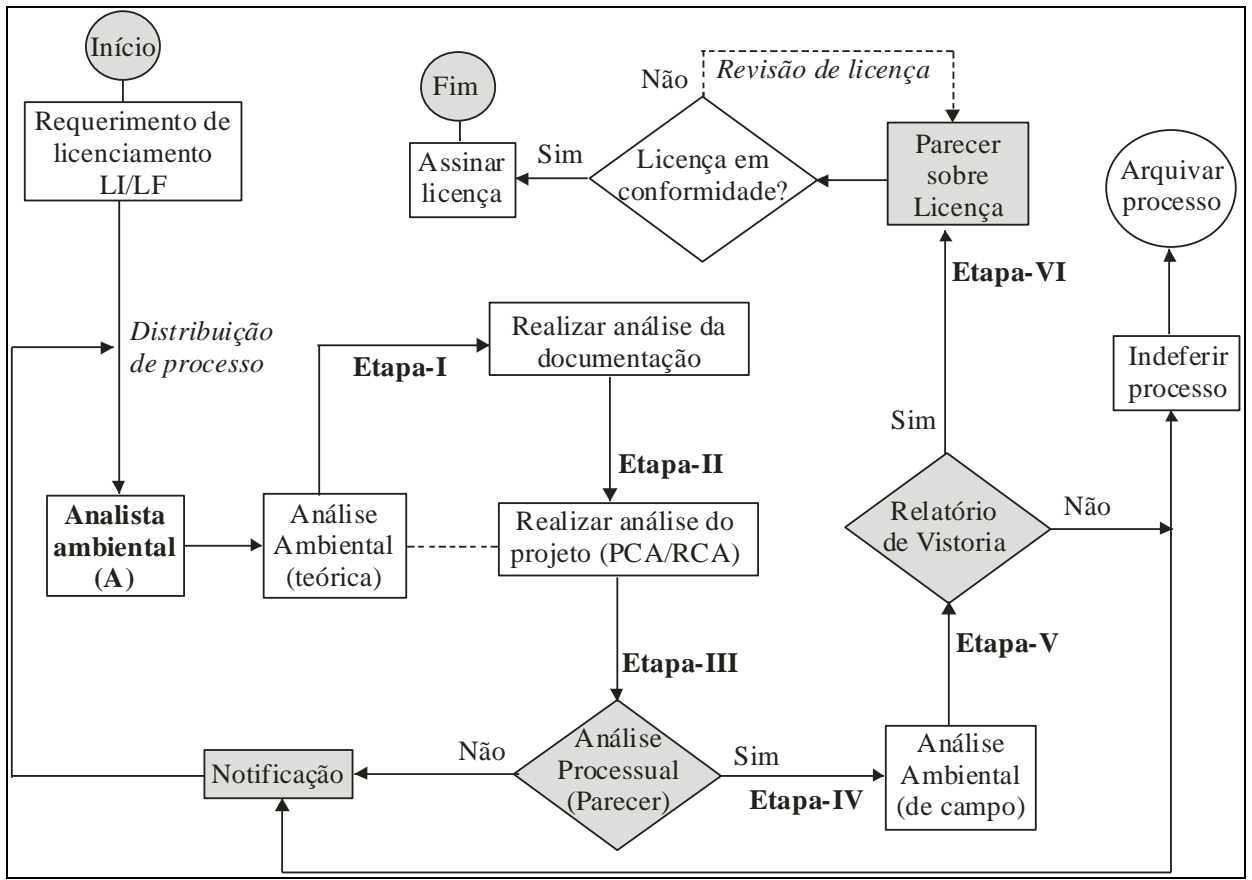

Figura 8: Modo de operação geral do processo de licenciamento convencional Fonte: Modificado de Araújo (2017, p.67).

\section{Considerações finais}

A reflexão empreendida neste artigo proporcionou o reconhecimento das seguintes características gerais sobre o processo de licenciamento ambiental do setor mineral goiano: a) da grande potencialidade do setor de mineração em Goiás e sua relevância no cenário brasileiro, posicionado como terceiro maior produtor mineral. $\mathrm{O}$ que indica a grande responsabilidade do órgão ambiental de Goiás para preservação do meio ambiente no Brasil e instituição formadora de opinião perante o cenário nacional; 
b) do predomínio quantitativo e maior demanda de processos de licenciamento junto ao órgão ambiental goiano para substâncias minerais de uso direto na construção civil e indústria agropecuária, como areia, argila, calcário e produção de agregados. $\mathrm{O}$ que pressupõe uma prioridade para organização do licenciamento ambiental de tais substâncias minerais e atividades, perante as demais; c) da inexistência de critérios legais em âmbito estadual para classificação das atividades e empreendimentos minerários e seu impacto ambiental para instrução do processo de licenciamento junto ao órgão ambiental de Goiás. Destaca-se aqui também, que o uso inadequado de uma informação ou categoria de substâncias minerais para o licenciamento, dentre outros aspectos, além de camuflar a sua estatística real, dificulta o monitoramento e fiscalização das atividades do setor mineral licenciadas, ou seja, contribui para a degradação ambiental, como é o caso da não distinção entre extração de areia "em leito de rio" e "em cava" para visualização das estatísticas e planejamento para o setor. Entende-se aqui, que a definição formal do processo de licenciamento, o estabelecimento de regramento e classificação ambiental das atividades minerárias, com consequente divulgação em formato didático e acessível a todos, afloram como os maiores desafios para o licenciamento ambiental realizado em Goiás.

\section{Referências}

ARAÚJO, D. Educação no processo de licenciamento ambiental-uma reflexão sobre o setor de mineração em Goiás. Dissertação (mestrado). Unicamp, Instituto de Geociências. Campinas, SP. 2017. Disponível em: < http://repositorio.unicamp.br/jspui/handle/REPOSIP/322025>Acesso: 11.11.2017.

BITAR, O.Y. Avaliação da recuperação de áreas degradadas por mineração não região metropolitana de São Paulo. Tese (doutorado). Escola Politécnica da Universidade de São Paulo. São Paulo,SP, 1997. Disponivel em:

<http://www.teses.usp.br/teses/disponiveis/3/3134/tde-25102001-165349/pt-br.php> Acesso: 11.11.2017.

BRASIL. Constituição da República Federativa do Brasil, 1988. Disponível em: $<$ http://www.br/ccivil_03/constituicao/constituicaocompilado.htm Acesso: 11.11.2017.

BRASIL. Código de Mineração Brasileiro. Decreto-lei № 227, de 28 de fevereiro de 1967. Disponível em: <http://www.planalto.gov.br/ccivil_03/decreto-lei/Del0227.htm > Acesso: $11 / 11 / 2017$.

BRASIL. Decreto $n^{\circ}$ 99.274, de 06 de junho de 1990. Poder Executivo. Disponível em: < http://www.planalto.gov.br/ccivil_03/decreto/antigos/d99274.htm > Acesso: 23.12. 2016.

BRASIL. Ministério de Meio Ambiente. Conselho Nacional do Meio Ambiente (CONAMA). Resoluções. 1997. Disponível em:

<http://www.mma.gov.br/port/conama/legiano.cfm?codlegitipo=3> Acesso: 11.11.17. 
BRASIL. Lei $n^{\circ} 12.651$, de 25 de maio de 2012. Dispõe sobre a proteção da vegetação nativa. Poder Executivo. Brasília, DF. 2012. Disponível em: <http://www.planalto.gov.br/ccivil_03/_ato2011-2014/2012/lei/L12651compilado.htm> Acesso: 11.11.17.

BRASIL. Lei Complementar $n^{\circ}$ 140, de 08 de dezembro de 2011. Poder Executivo. Brasília, DF. 2011. Disponível em: 〈http://www.planalto.gov.br/ccivil_03/leis/LCP/Lcp140.htm> Acesso: 11.11.17.

CARMO, H; FERREIRA, M. M. Metodologia da investigação (guia para autoaprendizagem). Lisboa. Unversidade Aberta. 1998, 353p.

CECAV/ICMbio - Centro Nacional de Pesquisa e Conservação de Cavernas/Instituto Chico Mendes de Conservação da Biodiversidade. IV Curso de Espeleologia e Licenciamento Ambiental. Belo Horizonte, 22 a 27 de abril de 2013. Disponível em: < http://www.icmbio.gov.br/cecav/images/stories/downloads/IV_Curso_de_Espeleologia_e_Li cenciamento_Ambiental.pdf > Acesso: 22.11.2016.

CETESB. Companhia Ambiental do Estado de São Paulo. Decisão de Diretoria $n^{\circ}$ 025/2014/CI, de 29 de janeiro de 2014. 2014a. São Paulo. Disponível em: < https://cetesb.sp.gov.br/wp-content/uploads/2018/01/Decis\%C3\%A3o-de-Diretoria-25_14Licenciamento-Minera\%C3\%A7\%C3\%A3o.pdf > Acesso: 09.09.2018.

CETESB. Companhia Ambiental do Estado de São Paulo. Manual para elaboração de estudos para licenciamento com Avaliação de Impacto Ambiental. 2014b. São Paulo. Disponível em: < http://licenciamento.cetesb.sp.gov.br/cetesb/documentos/Manual-DD-21714.pdf > Acesso: 09.09.2018.

DNPM. Departamento Nacional de Produção Mineral. Sumário mineral. Brasília, DF. 2015a. Disponível em: <http://www.dnpm.gov.br/dnpm/colecoes/colecao-de-sumarios-sumariomineral> Acesso: 24.05.2016.

DNPM. Departamento Nacional de Produção Mineral. 2015. Desempenho do setor mineral GO e DF. 2015b. Brasília, DF. Disponível em: <http://www.anm.gov.br/dnpm/publicacoeseconomia-mineral/desempenho-mineral-go-df-2015.pdf/view> Acesso: 24.05.2016.

DNPM. Departamento Nacional de Produção Mineral. Portaria $n^{\circ}$ 144, de 03 de maio de 2007. Brasília, DF, 2007. Disponível em <http://www.anm.gov.br/acesso-ainformacao/legislacao/portarias-do-diretor-geral-do-dnpm/portarias-do-diretor-geral/portariano-144-em-03-05-2007-do-diretor-geral-do-dnpm/view> Acesso: 09.09.2018.

FONSECA, F.F.A. Mineração e ambiente. In: Tauk-Tornisielo, M.; Gobbi, N.; Fowler, H.G. (Orgs.) Análise ambiental: uma visão multidisciplinar. ( $2^{\circ}$ ed. Revisada e ampliada). São Paulo: Editora da Universidade Estadual Paulista, 1995, pp.177-181.

FREIRE, P. A importância do ato de ler. 51ª edição. São Paulo: Cortez, 2011. 
GOIÁS. Secretaria do Meio Ambiente e dos Recursos Hídricos (SEMARH). Portaria Estadual SEMARH $n^{\circ}$ 010, de 25 de fevereiro de 2010. 2010. Disponível em: < <http://www.secima.go.gov.br/pagina/ver/13105/legislacao> Acesso: 23.12.2016.

JACOBI, P.R. Educação ambiental, cidadania e sustentabilidade. Cadernos de Pesquisa. Fund. Carlos Chagas, n.118, 2003, p. 189-205. Disponível em: <http://www.scielo.br/pdf/cp/n118/16834.pdf>. Acesso: 24.05.2016.

JACOBI, P.R. Educação ambiental: o desafio da construção de um pensamento crítico, complexo e reflexivo. Educação e Pesquisa, v.31, n.2, 2005, p. 233-250. Disponível em: < http://www.scielo.br/pdf/ep/v31n2/a07v31n2 > Acesso: 24.05.2016.

LOUREIRO, C.F.B. Educação ambiental no licenciamento: uma análise crítica de suas contradições e potencialidades. Sinais Sociais (Rio de Janeiro), v.5, n.14, 2010, p.10-35. Disponível em: < http://www.sesc.com.br/wps/wcm/connect/49215b89-c03f-4259-93d0375e3d5b2e28/14.pdf?MOD=AJPERES\&CACHEID=49215b89-c03f-4259-93d0375e3d5b2e28 >. Acesso: 24.05.2016.

MACEDO, A.J.B; BAZANTE, A.J.; BONATES, E.J.L. Seleção do método de lavra: arte e ciência. Revista da Escola de Minas, , Ouro Preto, MG. 54(3), 2001, p. 303-307. Disponível em: <http://www.scielo.br/scielo.php?script=sci_arttext\&pid=S037044672001000300010\&lng=en\&nrm=iso\&tlng=pt> Acesso: 22.11.2016.

PIRANHA, J.M., CARNEIRO, C.D.R. O ensino de geologia como instrumento formador de uma cultura de sustentabilidade. Revista Brasileira de Geociências. 39(1), 2009, p.129-137. Disponível em : <http://ppegeo.igc.usp.br/index.php/rbg/article/view/7634> Acesso: 28.05.2016.

PONZILACQUA, M.H.P. Sociologia ambiental do direito: análise sociojurídica, complexidade ambiental e intersubjetividade. Petrópolis RJ: Vozes, 2015.

QUINTAS, J.S. Educação no processo de gestão ambiental: uma proposta de educação ambiental transformadora e emancipatória. In: Layrargues, P.P.(coord). Identidades da educação ambiental brasileira. Brasília, DF. MMA. Diretoria de Educação Ambiental. 2004, p.113-139. Disponível em: <http://www.mma.gov.br/estruturas/educamb/_arquivos/livro_ieab.pdf>. Acesso: 11.11.2017.

SANCHEZ, L.E. Avaliação de impacto ambiental: conceitos e métodos. São Paulo: Oficina de Textos, 2008.

SILVEIRA, V.F. Geoprocessamento como instrumento de gestão ambiental. In: Philippi Jr., Romero MA, Bruna C.G. (orgs.). Curso de gestão ambiental. Barueri, SP: Manole, 2004, p.946968. 


\section{Dalmo de Araújo.}

Graduado em Geologia pela Universidade de São Paulo/USP. Mestre em Ensino e História de Ciências da Terra pela Universidade Estadual de Campinas/UNICAMP. Analista Ambiental junto à Secretaria de Meio Ambiente, Recursos Hídricos, Infraestrutura, Cidades e Assuntos Metropolitanos do Estado de Goiás/SECIMA.

Núcleo de Licenciamento da SECIMA, $11^{\mathrm{a}}$ Avenida, 1272, Leste Universitário, Goiânia, GO, CEP74605-060.

E-mail: dalmodearaujo@gmail.com

Recebido para publicação em maio de 2018 Aprovado para publicação em setembro de 2018 